\title{
Effects of Moisture and Mycorrhiza on Stomatal Conductance and Xylem Pressure Potential of Faidherbia albida (Del.) A. Chev.
}

\author{
${ }^{* 1}$ M.A. Shinkafi and ${ }^{2}$ A.M. Aduradola \\ ${ }^{1}$ Department of Forestry and Fisheries, Usmanu Danfodiyo University, Sokoto, Nigeria \\ ${ }^{2}$ Department of Forest Resources Management, Federal University of Agriculture, Abeokuta, Nigeria \\ [*Correspondence Address: walinshinkafi@ hotmail.com; $\mathbf{0}+\mathbf{2 3 4}(\mathbf{0}) \mathbf{8 0 3 6 9 8 3 2 8}$ ]
}

\begin{abstract}
The effects of moisture and mycorrhizal inoculation on stomatal conductance and xylem pressure potential of Faidherbia albida (Del.) A. Chev. were investigated in the semi arid environment of Sokoto, Nigeria. A complete randomized block design with five replications and factorical combination of three watering regimes (daily for unstressed plant, twice weekly for partially stressed plants and once a week for moisture stressed plants) and three mycorrhizal treatments namely; endomycorrhizal plants, ectomycorrhizal plants and non mycorrhizal plants were used. Both the ecto and endo mycorrhizae significantly $(\mathrm{P}<0.05)$ affected the Stomatal Conductance and Xylem Pressure Potential of the plant even under stressed conditions. The use of mycorrhiza is thus recommended as a strategy for efficient water utilization and water conservation.
\end{abstract}

KEYWORDS: Faidherbia albida, mycorrhiza, stomatal conductance, xylem pressure

\section{INTRODUCTION}

The most critical environmental factor affecting the growth and development of trees in the tropics is water availability (Nwoboshi, 1982). Water enhances starchiness in the leaf tissue in many species while its deficiency induces conversion of starch to sugar. In wilting leaves, most of the starch is converted into sugars, which lead to rise in the respiration rate. Similarly, various vital process in plants such as cell division, cell elongation and stem as well as leaf enlargement are dependent upon moisture availability (Kadmon, 1995). Insufficient moisture below the critical level is causes changes in cell structure leading to the death of plants (Lewty, 1990). Price et al. (1986) observed an increase in photosynthesis and tree growth due to an increase in soil moisture content in a 32-year old Pinus mensiesii plantation. This is because water maintains the leaf turgor for stomata opening and subsequent carbon dioxide influx (Boomsa and Hunter, 1990). Moisture stress causes reduction in general physiological activities and thus growth and development of plants. Under extreme water deficits, photosynthesis and other essential processes are directly inhibited leading to stomata closure and, thus, reduction in assimilation rate (Vogt, 2003; Vogt et al., 2007).

The role of mycorrhiza in enhancing water retention ability of plants and the desirability of its use in the tropics are also well documented in literature (Odeyinde and Ekwebelem, 1982). This study investigated the effects of moisture and mycorrhizal inoculation on Stomata Conductance and Xylem Pressure Potential in young seedlings of Faidherbia albida.

\section{MATERIALS AND METHODS}

A randomized complete block design was used, with five replications and a factorial combination of three watering regimes (daily for unstressed plants -3 , twice weekly for partially-stressed plants -2 and once a week for moisture-stressed plants -1) and three mycorrihizal treatments (endomycorrhiza -ENM, ectomycorrihiza -ECM and non-mycorrihiza plants -NM) to determine the effects of moisture stress and inoculation with mycorrihiza on stomatal conductance and xylem pressure potential (XPP) in $F$. albida seedlings.

Seedlings were grown at the botanical garden of Usmanu DanFodiyo University, Sokoto, under an average day/night temperatures of $43^{\circ} \mathrm{C}$ and relative humidity of $45 \%$. They were watered regularly for 2 weeks before moisture stress treatment of watering once a week began. Soil moisture at pot capacity was $30 \pm(2) \%$. While the unstressed plants were watered daily, the moisture-stressed plants were watered at weekly intervals for 12 weeks. Measurements were made fortnightly starting from 4 weeks after germination. Diurnal fluctuations of stomatal 
conductance and xylem pressure potential were determined during a 12- hour photoperiod. Stomata conductance was measured with a LiCorLi-16000 Steady State Porometer (LiCor Inc., Nebraska, USA) on the abaxial surfaces of the fully expanded leaves of $F$. albida. The leaves of $F$. albida were placed between the thermistor and the sensor for actual reading. Readings were taken by pressing a button. Stable readings were denoted by the sound of a double "beep", The AP4 cycling porometer provides an important tool for understanding the intricate web of mechanism that control the stomata behaviour. The instrument works by measuring the time it takes for a leaf to release sufficient water vapour to change the relative humidity in a chamber by a fixed amount. This is compared with a calibration plate of known resistance in order to derive the stomata resistance or conductance of the leaf.

Leaves Water Potential otherwise known as Xylem Pressure Potential was measured using a pressure bomb appraratus with the aid of nitrogen gas. Due to small nature of the leaves of $F$. albida, the entire leaflets were used for this measurement. The leaflets were placed in a cork in the pressure chamber apparatus. Reading were taken at the emergence of water bubbles through a small but sharp outlet on top of the chamber cup. Differences in physiological changes were tested for significance using analysis of varience (ANOVA). $\mathrm{P}<0.05$ was taken as a significant difference

\section{RESULTS AND DISCUSSIONS}

Diurnal variations in stomata conductance after twelve drought cycles are presented in Table 1. The results showed significant $\quad(\mathrm{P}<0.05)$ difference in the stomata Conductance of moisture-stressed $F$. albida plants (NMWI, ENMWI and ECMWI) at pre-sunrise (0600h), with the highest mean value recorded in ENMWI plants. However, the reverse is the case with the unstressed $F$. albida palnts (NMW3, ENMW3 and ECMW3) watered daily. In the case of partially stressed plants, the only significant difference recorded was in ENM2 plants. Unlike in the pre-sun rise values, the Stomata Conductance at mid-day (1200h) differed significantly $(\mathrm{P}<.0 .5)$ between inoculated and non-inoculated seedlings with the highest value recorded in the endomycorrihizal plants across the three watering frequencies. This phenomenon was also observed in the evening (1800h), with the endo-mycorrihiza inoculated plants having the highest mean values.

The diurnal variation in xylem pressure potential after twelve drought cycles is also presented in Table 2. The results showed significant differences $(\mathrm{P}<0.05)$ in the XPP of $F$. albida between inoculated and non-inoculated seedlings under stressed and partially stressed conditions. In both pre-sunrise and mid-day mean values, the NM and ECM plants had significantly $(\mathrm{P}<0.05)$ higher values than the ENM plants as opposed to stomata conductance. At the evening time, significant $(\mathrm{P}<0.05) \quad$ differences were also recorded in moisture stressed, partially and unstressed plants except in the case of $\mathrm{ENMW}_{3}$ and $\mathrm{ECMW}_{3}$ that had the same mean values.

Generally, there were significant differences in the Stomata Conductance and XPP of ENM, ECM and NMF $F$. albida plants except in the case of unstressed plants during the pre-sunrise $(0600 \mathrm{~h})$ periods. The result of the current findings did not agree with the work of Graham (2007) who reported no significant difference in the Stomata Conductance and XPP of VAM and NM in A. auriculoformis and G. sepium but our results are in agreement with the findings of Huang et al. (1985) who observed greater XPP at low soil water poterntial.

The higher stomatal closure in moisture-stressed NM plants than in the corresponding ENM and ECM plants, coupled with high XPP may represent an adaptive strategy in conserving water and preventing severe water losses. These findings are in conformity with the report of Osundina (1995) and Graham (2007) on A. auriculiformis and P. biglobosa respectively. The increased stomata conductance with reduced XPP in moisture-stressed ENM and ECM $F$. albida plants was probably to maintain higher water potential gradient for more efficient uptake, which suggest that mycorrhiza may be fundamentally significant under condition of restricted water supply (Osunobi and Mulongoy,

\section{CONCLUSIONS}

The significant differences in diurnal variations of both the stomatal conductance and XPP between ENM, ECM and NM plants is a clear indication 
of role of mycorrhiza in enhancing water utilization efficiency of the host plant. The higher stomata closure in drought- stressed NM plant than in the corresponding ENM and ECM plants, coupled with high XPP represents an adoptive strategy in conversing water and thereby preventing severe water losses. The differences in response of $F$. albida plants to the two kinds of mycorrhiza also justify the need for the selection of the most effective symbotic partners to maximize the benefits of their interaction with plants under restricted water supply.

Table 1: Diurnal variations in stomata conductance after twelve drought cycles

\begin{tabular}{|c|c|c|c|}
\hline \multirow{2}{*}{ Treatment } & \multicolumn{3}{|c|}{ Stomata Conductance at difference times of the day $\left(\mathrm{Molm}^{-2} \mathrm{~s}^{-1}\right)$} \\
\hline & 06:00 hr & 12:00hr & 18:00 hr \\
\hline $\mathrm{NMW}_{1}$ & $11.40^{\mathrm{C}}$ & $40.00^{\mathrm{h}}$ & $20.00^{\mathrm{h}}$ \\
\hline $\mathrm{NMW}_{2}$ & $20.00^{\mathrm{C}}$ & $80.00^{\mathrm{f}}$ & $40.00^{\mathrm{f}}$ \\
\hline $\mathrm{NMW}_{3}$ & $30.00^{\mathrm{a}}$ & $120.00^{\mathrm{c}}$ & $20.00^{\mathrm{c}}$ \\
\hline $\mathrm{ENMW}_{1}$ & $20.00^{\mathrm{C}}$ & $90.00^{\mathrm{e}}$ & $60.00^{\mathrm{d}}$ \\
\hline $\mathrm{ENMW}_{2}$ & $25.00^{\mathrm{b}}$ & $100.20^{\mathrm{d}}$ & $60.00^{\mathrm{d}}$ \\
\hline $\mathrm{ENMW}_{3}$ & $30.20^{\mathrm{d}}$ & $140.00^{\mathrm{a}}$ & $90.00^{\mathrm{h}}$ \\
\hline $\mathrm{ECMW}_{1}$ & $15.20^{\mathrm{d}}$ & $600.00^{\mathrm{g}}$ & $30.60^{\mathrm{g}}$ \\
\hline $\mathrm{ECMW}_{2}$ & $20.40^{c}$ & $90.00^{\mathrm{e}}$ & $50.80^{\mathrm{c}}$ \\
\hline $\mathrm{ECMW}_{3}$ & $20.20^{\mathrm{a}}$ & $130.00^{b}$ & $80.00^{\mathrm{b}}$ \\
\hline
\end{tabular}

Means a long the same raw with the same superscripts are not significantly different $(\mathrm{P}>0.05)$ DMRT

Table 2: Diurnal variations in Xylem Pressure Potential after twelve drought cycles

\begin{tabular}{lccc}
\hline & \multicolumn{2}{c}{ Xylem Pressure Potential at different times of the day (mpa) } \\
Treatment & $06: 00 \mathrm{hr}$ & $12: 00 \mathrm{hr}$ & $18: 00 \mathrm{hr}$ \\
\hline $\mathrm{NMW}_{1}$ & $1.50^{\mathrm{a}}$ & $2.79^{\mathrm{a}}$ & $1.40^{\mathrm{a}}$ \\
$\mathrm{NMW}_{2}$ & $1.00^{\mathrm{c}}$ & $2.00^{\mathrm{b}}$ & $1.40^{\mathrm{c}}$ \\
$\mathrm{NMW}_{3}$ & $0.20^{\mathrm{f}}$ & $10.2^{\mathrm{f}}$ & $0.30^{\mathrm{a}}$ \\
$\mathrm{ENMW}_{1}$ & $1.02^{\mathrm{C}}$ & $1.28^{\mathrm{c}}$ & $0.80^{\mathrm{d}}$ \\
$\mathrm{ENMW}_{2}$ & $0.70^{\mathrm{b}}$ & $0.50^{\mathrm{h}}$ & $0.40^{\mathrm{d}}$ \\
$\mathrm{ENMW}_{3}$ & $0.10^{\mathrm{g}}$ & $0.40^{\mathrm{c}}$ & $0.20^{\mathrm{h}}$ \\
ECMW $_{1}$ & $1.30^{\mathrm{b}}$ & $1.80^{\mathrm{c}}$ & $1.00 .^{\mathrm{b}}$ \\
ECMW $_{2}$ & $0.90^{\mathrm{d}}$ & $1.50^{\mathrm{d}}$ & $0.70^{\mathrm{c}}$ \\
ECMW $_{3}$ & $0.20^{\mathrm{f}}$ & $0.90^{\mathrm{g}}$ & $0.20^{\mathrm{h}}$ \\
\hline
\end{tabular}

Means a long the same raw with the same superscripts are not significantly different $(\mathrm{P}>0.05) \mathrm{DMRT}$

\section{REFERENCES}

Boosma, D.B. and I.R. Hunter (1990). Effects of water, nutrients and their interactions on tree growth and plantation forest managemement practice in Australia. Ecol. Mgnt. 30: 455-477.

Graham, J.H. (2007). Host determinations of mycorrhizal dependency. New Phytol 301: 1667- 1676.

Huang, R.S., W.K. Smith and R.S. Yost (1985). Influence of vesicular arbisucular mycorrhiza on growth, water relations and leaf orientation in Leuceana leucocephala (Lam) Wit. New Phytol. 101: 229 - 243.

Kadmon, R. (1995). Plant competition along soil moisture gradients: a field experiment with the desert annual Stipa capensis. Ecol. 83:252-262.

Lewty, M.J. (1990). Effects of water logging on the growth and water relations of Pinus tax. For. Eco. Mgnt. 30:189-201.

Nwoboshi, L.C. (1982). Indces of macronutrient deficiencies in Khaya senegalensis. Plant Anal. 13(8): 666-682. 
Odeyinde, M.A. and S.A. Ekwebelem (1982). In search of a suitable pine mycorrhizal fungus in the high forest zone of Nigeria. For. Sci. 39: $93-97$.

Osundina, M.A. (1995). Response of seedling of Parkia biglobosa (African Locust Beam) to drought and inoculation with vesiculararbusucular mycorrhiza. Nig. J. Bot. 8: 110.

Osunobi. O. and K. Mulongoy (1991). Response of two acacia species to drought and inoculation with ecto-mycorrhizal fungus. In D.L., Kieste, P.B. Cregan (eds). The rhizosphere and plant growth. Kluwer Academics Publishers, Dordecht. Pp 362 375.
Price, D.T., T.A. Balck and F.M. Kelliher (1986). Effects of Salal under story removal on photosynthesis rate and stomata conductance of young Douglas-fir trees. Can. J. For. Res. 16: 90-97.

Vogt, K.A. (2003). Dynamics of Ectomycorrhiza in Abies amabilis stand: The Role of Cenococcum graniforms. Halartic Ecol. 24: $1-8$.

Vogt, K.A., C.C. Grier and C.E. Meir (2007). Physological role in net primary production and nutrient cycling in abies amabilis ecosystems in western Washington. Ecol. 63(2): $350-370$. 